\title{
New Lightweight Optimization Method Applied in Parts Made by Selective Laser Sintering and Polyjet Technologies
}

\section{Rubén Paz}

Departamento de Ingeniería Mecánica, Universidad de Las Palmas de Gran Canaria, 35017 Las Palmas G.C., Spain, e-mail: rpaz@lfi.gi.ulpgc.es

\section{Mario D. Monzón}

Departamento de Ingeniería Mecánica, Universidad de Las Palmas de Gran Canaria, 35017 Las Palmas G.C., Spain, e-mail:mmonzon@dim.ulpgc.es

Antonio N. Benítez

Departamento de Ingeniería de Procesos, Universidad de Las Palmas de Gran Canaria, 35017 Las Palmas G.C., Spain, e-mail: abenitez@dip.ulpgc.es

Begoña González

University Institute of Computational Engineering (SIANI), Evolutionary Computation and Applications (CEANI), Universidad de Las Palmas de Gran Canaria, 35017 Las Palmas G.C., Spain,e-mail: bgonzalez@iusiani.ulpgc.es 


\title{
New Lightweight Optimization Method Applied in Parts Made by Selective Laser Sintering and Polyjet Technologies
}

\author{
The continuous evolution of materials and technologies of Additive \\ Manufacturing (AM) has led to a competitive production process even for \\ functional parts. The capabilities of these technologies for manufacturing \\ complex geometries allow the definition of new designs that cannot be obtained \\ with any other manufacturing processes. An application where this capability can \\ be exploited is the lightening of parts using internal structures. This allows to \\ obtain more efficient parts and, at the same time, reduce the costs of material and \\ manufacturing time. A new lightweight optimization method to optimize the \\ design of these structures and minimize weight while keeping the minimal \\ mechanical properties is presented in this paper. This method is based on genetic \\ algorithms (GAs), metamodels and finite element analysis (FEA). This \\ combination reduces the number of FEA simulations required during the \\ optimization process, thereby reducing the design time. This methodology is \\ experimentally applied to a reference geometry oriented both for Selective Laser \\ Sintering (SLS) and Polyjet technologies. In both cases an optimized and a non- \\ optimized design are manufactured and tested in order to experimentally compare \\ the stiffness results between them. The optimum design achieved a specific \\ stiffness $72.82 \%$ higher than the non-optimized design in the SLS case study, and \\ 3.14 times higher in the Polyjet case study.
}

Keywords: Additive Manufacturing, Lightweight Optimization, Genetic Algorithms, Finite Element Analysis

\section{Introduction}

Improvements in materials as well as the reliability and repeatability of Additive Manufacturing (AM) technologies (Kruth et al. 1998) have led to a steady increase in their use over the past decade (Gibson et al. 2009). Nowadays, the evolution of AM technologies allows their use even for manufacturing of functional parts, which has become the most important application of these techniques (Wong and Hernandez 2012). 
The capabilities of these processes have changed the design rules employed for conventional manufacturing processes. In Additive Manufacturing, the almost inexistent restrictions associated with the manufacturing process involve an enormous design freedom (freeform manufacturing) (Hopkinson et al. 2006). This freedom allows the production of complex parts impossible to achieve with conventional production processes. In this sense, one of the most interesting applications of these capabilities is the lightweight optimization of AM parts using internal cellular structures. This concept has been used in many cases related to tissue engineering (Yang et al. 2001, Sachlos and Czernuszka 2003, Yeong et al. 2004, Yoo 2011, Almeida and Bártolo 2013), but can also be applied in many other sectors such as automotive or aeronautic. This lightweight optimization can lead to a more efficient design due to weight reduction, which is a key factor in some applications. Moreover, the mass reduction enables cost savings related to material used and manufacturing time, which means that with the application of lightweight optimization, more competitive products can be produced and with faster time to market. However, the lightweight optimization requires an initial design effort as well as the time required for the optimization process.

For this reason, in order to reduce the time and cost of design, a new optimization program based on GAs and surrogate model is proposed, taking advantage of the commercial software of 3D design and FEA to evaluate the quality of different designs. In order to facilitate the application of this methodology for any AM user, this program is integrated into the 3D design and FEA software through the Application Programming Interface, which provides a friendly and simple user interface.

\section{New lightweight optimization method}

Despite some authors have proposed very interesting methodologies for lightweight optimization with truss structures applied in AM, these methodologies are complex and 
require interaction between different software. Additionally, main innovations in these references are related to the geometry modelling to define the truss structure (Wang and Rosen 2001, Wang et al. 2005, Rosen 2007, Chu et al. 2008, Chu et al. 2010, Chang and Rosen 2013). However, in this paper the objective is to optimize the variables of the internal structure according to the parameterized geometry proposed by the user in commercial 3D CAD software, which means that the most important issue is the optimization method. On the other hand, there are many topology-based commercial optimization software that remove the low-stressed zones to reduce the weight. However, these methods lead to rough designs or even unfeasible designs that cannot be manufactured even by AM. Although these limitations are being reduced more and more with the new AM-oriented commercial tools (such as 3-maticSTL, Materialise), the external surface can suffer modifications with this type of topology optimization. Nevertheless, the methodology presented in this paper is focused on parametric optimization in order to keep invariable the external surface and also to achieve the final optimum without any subsequent step.

As commented in section 1, FEA are used to evaluate the quality of proposed designs. Hence, modifying the parameters defined by the user in the CAD/FEA software, it is possible to change the design of the geometry and calculate the mechanical performance. Taking advantage of these tools, it is aimed to carry out an automatic optimization process (Dai et al. 2005, Marjanovic et al. 2009), reducing the optimization time as much as possible. Some authors (Roman Gatzi 2000) have applied genetic algorithms to optimize their designs. In this case, FEA is used to evaluate the fitness function of each individual proposed during the genetic algorithm evolution. However, this implies hundreds of FEA, which leads to an excessive consumption of processing time. To avoid this, some other authors (Jin et al. 2001, Zhu et al. 2009, Lee 
et al. 2010) have proposed the use of metamodels to reduce the number of computationally expensive FEA simulations and thereby reduce the optimization time. For this reason, the optimization methodology proposed in this paper combines the potential of GAs, surrogate models and FEA to reduce optimization time.

\subsection{Proposed methodology}

The proposed methodology is divided into 3 different phases:

(1) Initial design of experiments (DOE). In this phase some designs are calculated by FEA in order to obtain data to create the metamodel. This DOE is subdivided into 3 stages. In the first one, the points with all variables at their lowest value, mean value and maximum value are evaluated. This means that 3 points are simulated. The next stage of the DOE consists of applying GA with binary coding to add 'n' new points ( $\mathrm{n}=$ number of design variables). A 0 means a variable at its lowest value, and 1 at its maximum value. This GA maximizes the difference of each variable compared with previous sampling points, which means that new points are added at the corners of the domain as far away as possible from the previous sampling points. Finally, 'n' new points are added in the last part of the DOE. In this case, a GA with ternary coding is applied to maximize the difference of each variable compared with previous sampling points. But now ' -1 ' is related to the minimum value of the variable, ' 0 ' to the mean value and ' 1 ' to the maximum value. Furthermore, the GA penalizes designs with no gene at its mean value in order to add sampling points at different levels.

(2) Feasible/unfeasible border approximation by GAs. After the initial DOE, a new phase is accomplished. This consists of creating a Kriging metamodel with a 
linear regression model and an exponential correlation model, using all available data from the DOE. This metamodel is used to evaluate the fitness function during the evolution of a GA. This GA minimizes mass and penalizes individuals if any constraint is not satisfied. Additionally, in the first iteration of this phase, individuals close to the best design evaluated at earlier stages are penalized in order to explore new regions of the search space. Finally, the optimum achieved is simulated and the result is used to update the Kriging. This GA is repeated many times, but penalizing proximity to points added in this phase (a similar concept to niche sharing) (Della Cioppa et al. 2004) in order to explore new regions of the feasible/unfeasible border (Rubén et al. 2013). Once ' $n$ ' points have been added at this stage, the GA is applied again but without proximity penalty until achieving an optimum in which the mean absolute percentage error of the results estimated by Kriging, are less than 5\% compared to the simulation results.

(3) Final optimization by GAs. The last stage of the program consists of a GA similar to the previous phase (without proximity penalty). The Kriging metamodel is employed again to evaluate the fitness function of the GA individuals. The optimum achieved is simulated. This design will be the optimum if it is better than the best design of the previous stages of the optimization program. Otherwise, this GA is repeated until the best design of previous stages is improved. However, if more than ' $5+\mathrm{n}$ ' points have been simulated in this phase without enhancing the best design, and at least one of them was a feasible design, then this best design will be the final optimum.

The GAs applied in these 3 phases were based on a population of 100 individuals and maximum number of generations of 100 . The selection was carried out with a 
tournament selection of 2 individuals. The cross and mutation probabilities were $50 \%$ and $60 \%$ respectively. Elitism was also applied.

In the case of the GAs of the last 2 phases of the optimization program, arithmetic crossover was used and the mutation amplitude was $50 \%$. However, in the GAs of the DOE, partition and recombination crossover was employed because of the binary and ternary encoding. Moreover, the mutation consists of changing the gen value in the binary encoding, and randomly modifying the gen to the other 2 possible values (50\% probability) in the ternary encoding.

This optimization strategy was integrated into the CAD/FEA software via the Application Programming Interface. This application enables programming to automate the $\mathrm{CAD} / \mathrm{FEA}$ software through multiple functions available that can be called from different programming languages such as Visual Basic. Additionally, the Matlab Window application is automatically employed in real time during the optimization problem to carry out the Kriging metamodel (Lophaven et al. 2002, S N Lophaven 2002). The user defines the geometry, parameters and numerical analysis following certain conventions to correctly apply the optimization program. Once the geometry, parameterization and FEA are defined, the user executes the optimization problem and also introduces certain data needed to start the optimization, such as the number of variables and their lower and upper limits, the number of constraints with their limit values and feasible zones, and the maximum length of the finite element for the mesh generation.

\subsection{Comparison with other optimization methods}

The proposed methodology was compared with 2 optimization methods available in commercial software of CAD/FEM (SolidWorks): the "high quality" method, based on 
DOE of Box-Behnken and estimation of the optimum by response surfaces, and the "fast result" method, based on DOE of Rechtschaffner and optimum search by response surface estimation.

These 3 methods were tested in 7 different examples with complex geometries (Figure 1) and with different number of variables, from 3 to 20. In all the case studies the proposed method achieved a solution to the optimization problem while the other methods were limited depending on the number of variables, which means that the presented methodology is more versatile than these 2 commercial methods. Moreover, the optimum achieved by this method was always better than the optimum of the "high quality" method, improving it up to $3.41 \%$ and reducing the sampling required from $88 \%$ to 3.8 times. Likewise, the new method obtained a better solution (up to 6\%) than the "fast result" method, reducing also the sampling up to $76 \%$ in some cases. Although these commercial methodologies are widely used when a low sampling intensity is required, the developed method improved the results both in terms of quality of the optimum and sampling intensity.

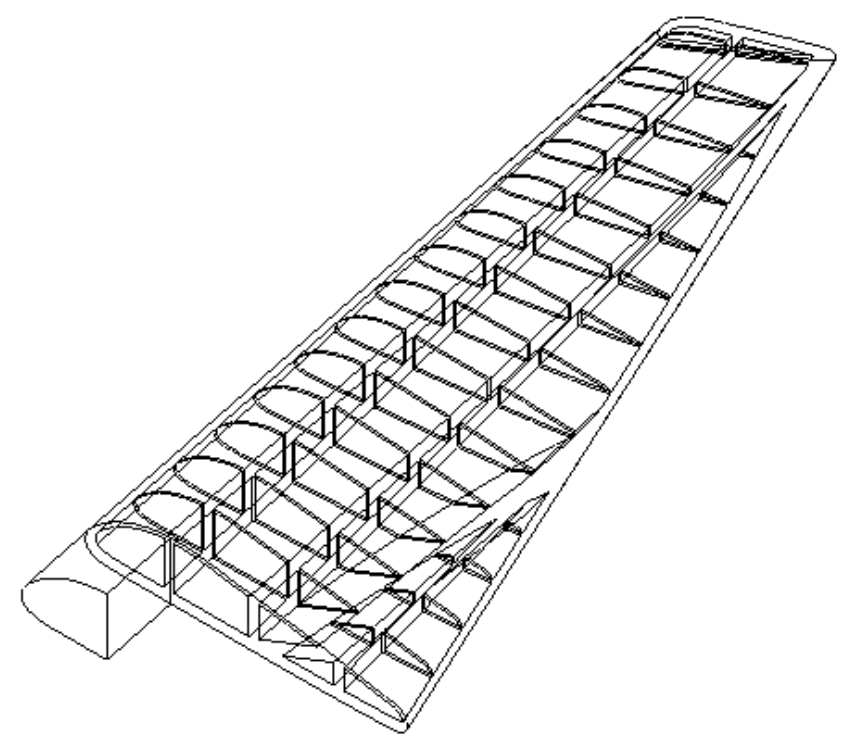

Figure 1. Example of complex geometry used to compare the 3 optimization methods. 


\section{Case study geometry}

The geometry selected for this case study was a squared prism of $40 \times 40 \times 170 \mathrm{~mm}^{3}$. This geometry is supported by 2 plaques with a distance of $160 \mathrm{~mm}$ between contact zones. Additionally, a punch is employed to apply a force on the upper face of the geometry (Figure 2). This punch is located in the middle of the geometry to apply the force in the midsection. For the FEA, a vertical force of $500 \mathrm{~N}$ is applied on this punch. Material employed for the 2 plaques and punch was Al EN-AW 5083.

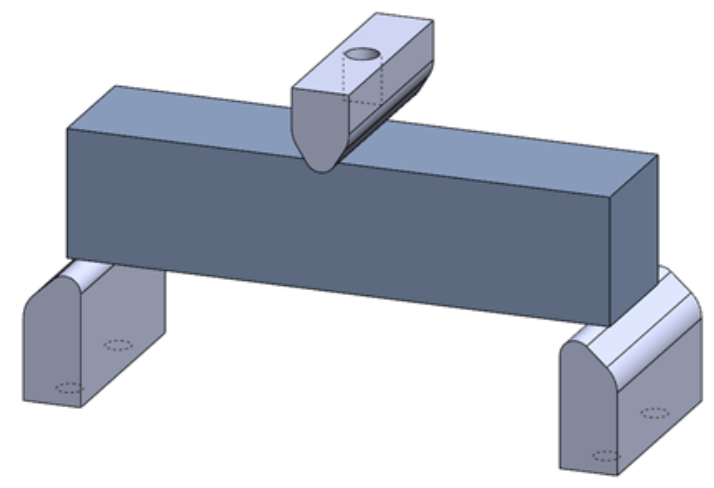

Figure 2. Case study geometry with supports and punch.

The objective is to minimize the weight of the part but keeping the maximum deflection lower than $0.5 \mathrm{~mm}$.

Two technologies were studied with this case study, the first by SLS and the second by Polyjet. In both cases, the design of the internal structure is symmetrical to the middle cross section and to the middle longitudinal section. Therefore, symmetry conditions were applied in the FEA to simplify the model. In addition, the same zones and hollows for removing support material were defined in both cases (SLS and Polyjet) (Figure 3). The type of mesh selected was the curvature-based mesher. This mesher automatically refines the mesh in zones with high curvature. The main parameters of this mesher are the maximum and minimum element size. However, in this case the minimum element size was defined as one fifth of the maximum element size. Therefore, the key parameter is the maximum element size. Different values of this parameter were proved 
until selecting a value of $5 \mathrm{~mm}$. This element size achieved results with a deviation lower than $2 \%$ compared with the results of the smallest element size proved $(1 \mathrm{~mm})$, but reducing the calculation time more than 20 times.

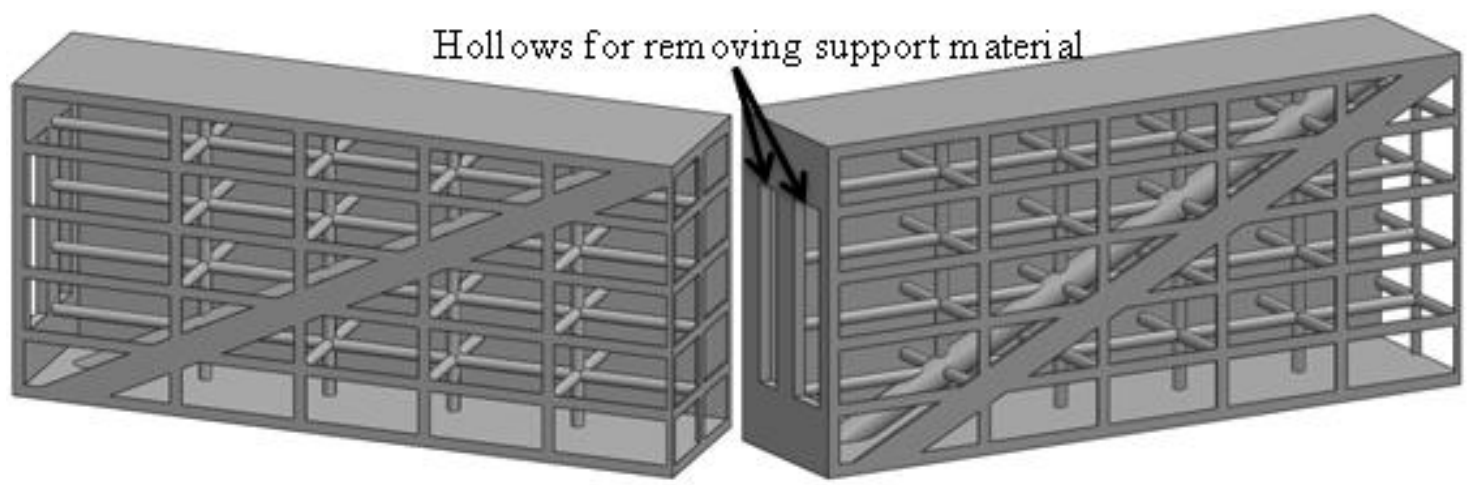

Figure 3. Case study geometry with symmetrical simplification and hollows for removing support material.

\section{SLS case study}

The geometry described in section 3 was lightened with an internal parameterized structure to be optimized. Three replicas of the optimum design were manufactured. Additionally, a non-optimal design evaluated during the optimization process was also manufactured (3 replicas). These parts were tested under flexural load.

\subsection{Geometry}

The lightweight design of the internal structure is shown in Figure 4. This design has a total of 23 variables associated to the wall thickness of the external faces (variables from 1 to 10) and the diameter of the bars in different groups (variables from 11 to 23). 


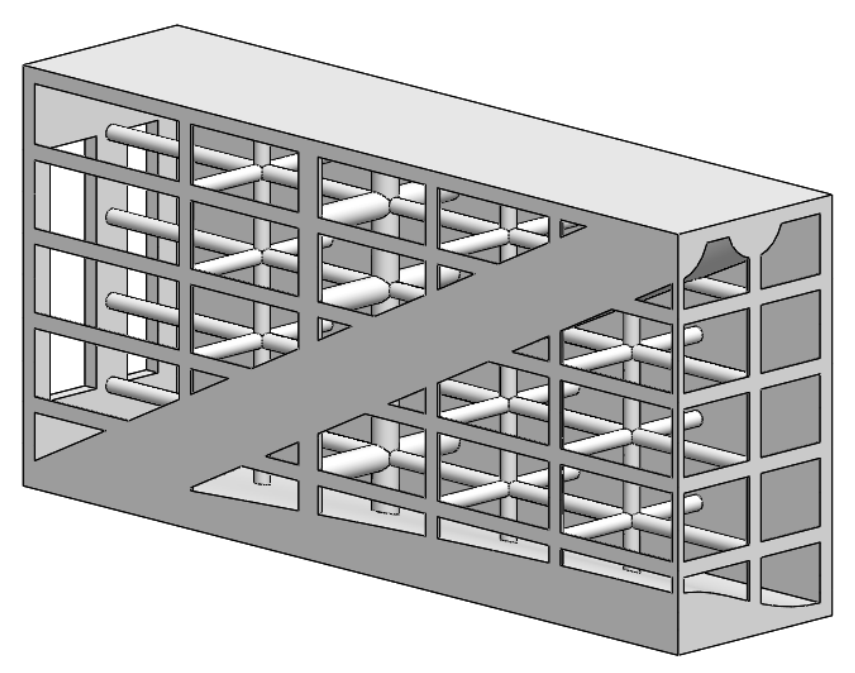

Figure 4. SLS case study geometry.

According to the symmetry conditions, this geometry was modelled by fixing the lower face of the support, constraining the displacement in the normal direction of all faces in the planes of symmetry, and applying a force of $125 \mathrm{~N}$ (double symmetry) on the upper face of the force plaque (Figure 5). A non-penetration type of contact was defined between the different parts. The material was polyamide PA3200GF, with a modulus of elasticity for the FEA of 1990MPa (experimental evidence provided by the manufacturer), and a Poisson's ratio of 0.34, typically employed in PA (Muraru et al. 2010). The density was $1.22 \mathrm{~g} / \mathrm{cm}^{3}$.

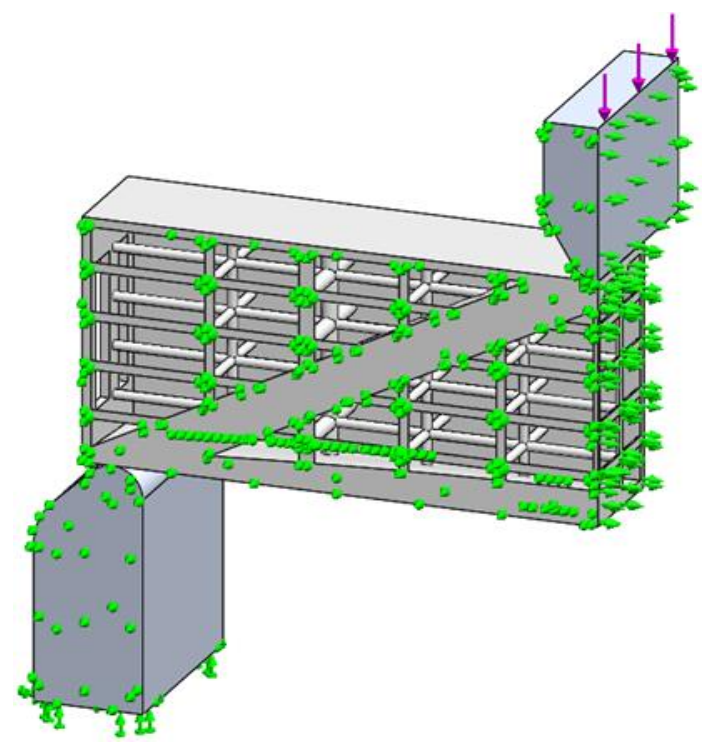

Figure 5. Boundary conditions for the FEA. 


\subsection{Optimization}

The geometry defined in section 4.1 was optimized with 5 runs of the program described in section 2 . The most representative optimum in terms of mass among the 5 optima achieved was selected to be manufactured. In this case, it was reached in execution number 1 , with a mass of $23.040 \mathrm{~g}(0.49 \mathrm{~mm}$ deflection), while the average value of the 5 optima was $23.052 \mathrm{~g}$, and was reached after 90 sampling points (the highest among the 5 executions), with a total optimization time of $88.3 \mathrm{~min}$ (Figure 6). Figure 7 shows the value of the design variables of the 5 optima. Here it can be observed how most of variables change considerably among optima.

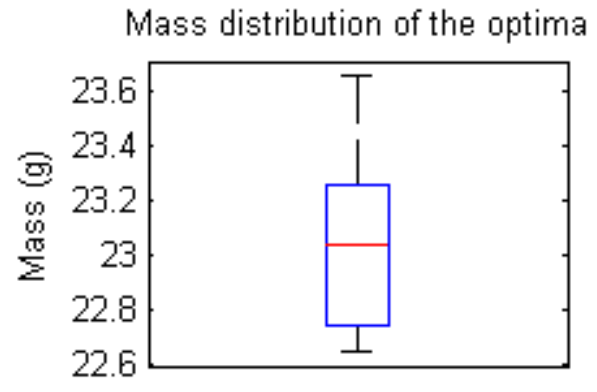

(a)

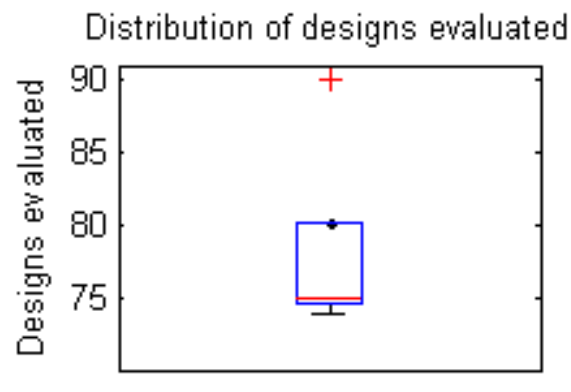

(c)
Deflection distribution of the optima

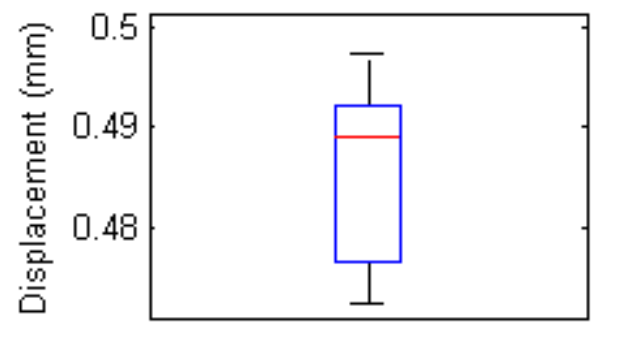

(b)

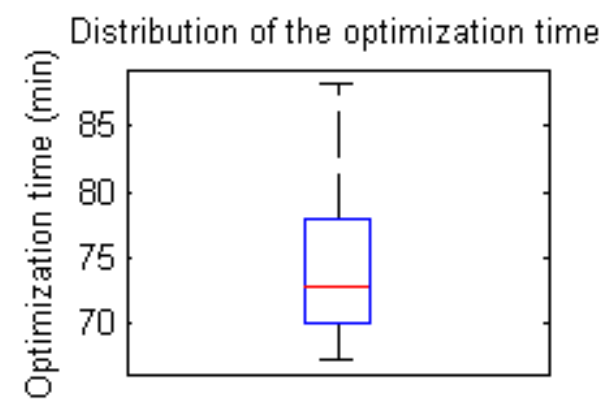

(d)

Figure 6. Distribution of mass of the optima (a), distribution of deflection of the optima (b), distribution of number of designs evaluated (c) and distribution of the optimization time (d) for the SLS case study. 


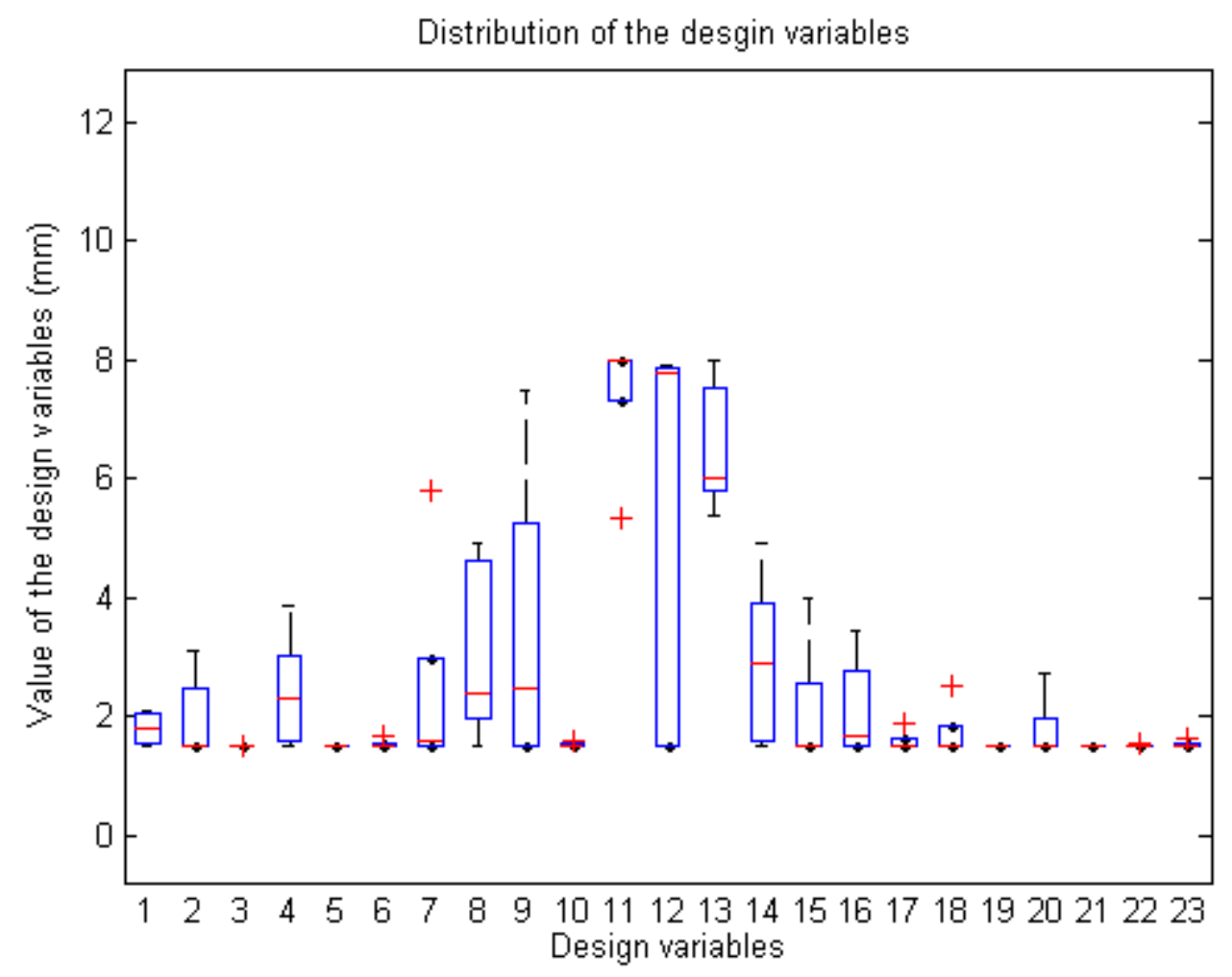

Figure 7. Distribution of the design variables of the 5 optima (SLS case study).

Apart from the optimum selected, a non-optimal design evaluated during execution 1 was also selected to be manufactured. The design selected was the number 12 for having the lowest specific stiffness among the designs evaluated. This design has a mass of $32.412 \mathrm{~g}$ and a deflection of $0.52 \mathrm{~mm}$.

Applying symmetry with respect to the two planes of symmetry, the optimum and non-optimum designs were defined. In Figure 8 and Figure 9 can be observed the optimum and non-optimum, respectively, with some transparent faces to show the internal structures. 


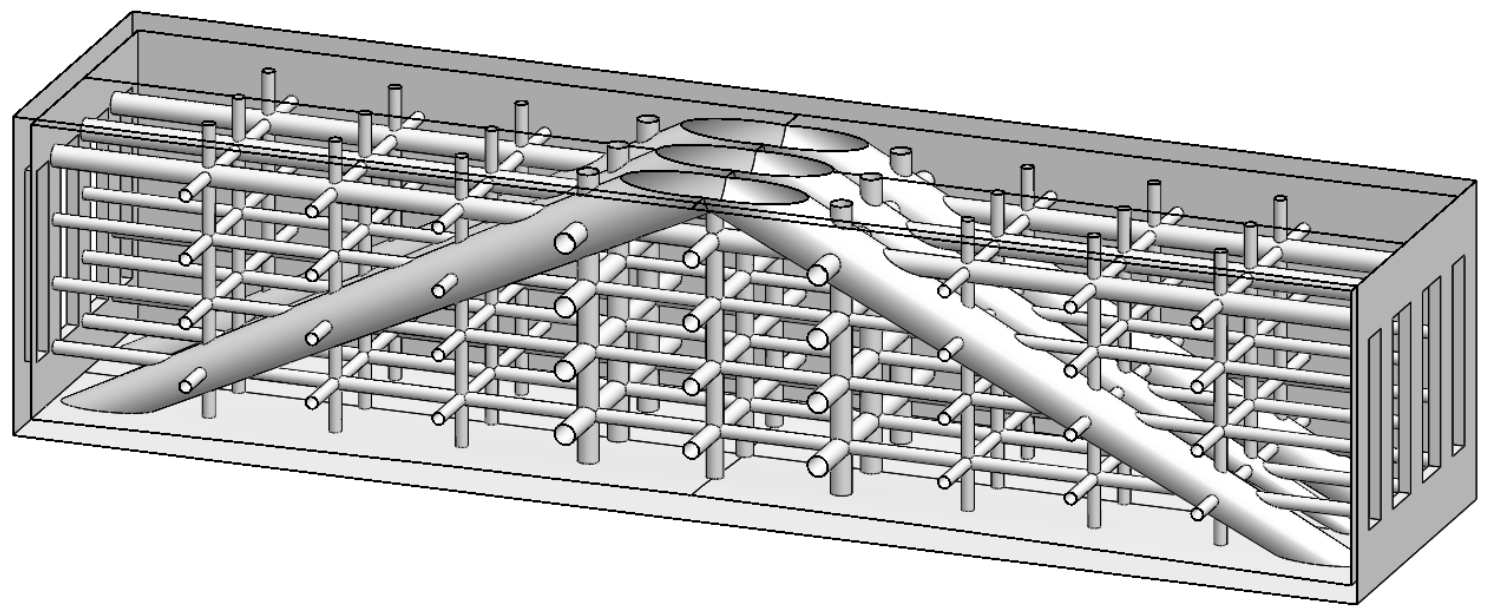

Figure 8. Optimum design selected (SLS case study).

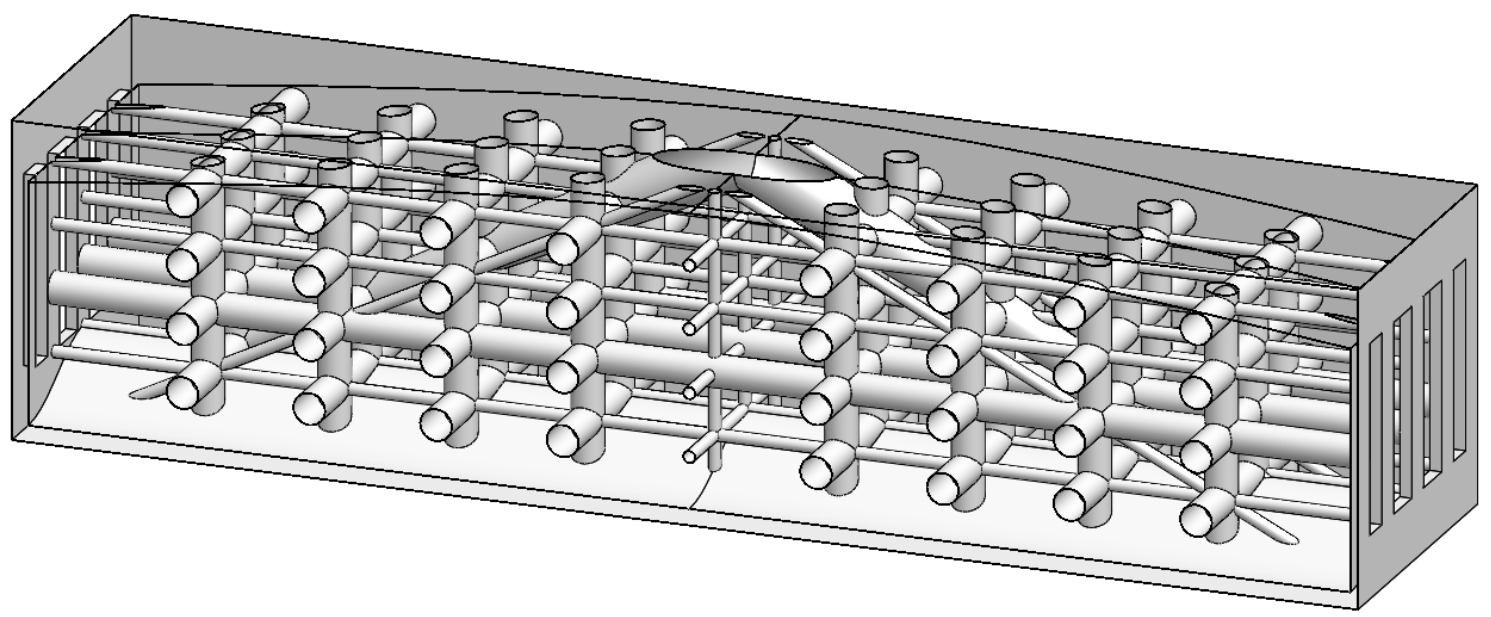

Figure 9. Non-optimum design selected (SLS case study).

\subsection{Parts manufacturing and flexural test}

Three replicas of both designs were manufactured in a SLS EOSint P380 machine, with a laser power of $13.225 \mathrm{~W}, 0.15 \mathrm{~mm}$ layer thickness and $50 \%$ of recycled material (PA3200GF). The optimal parts were codified with an "O" and non-optimal parts with an "N", while number 1 to 3 differentiate the 3 replicas (Figure 10). 


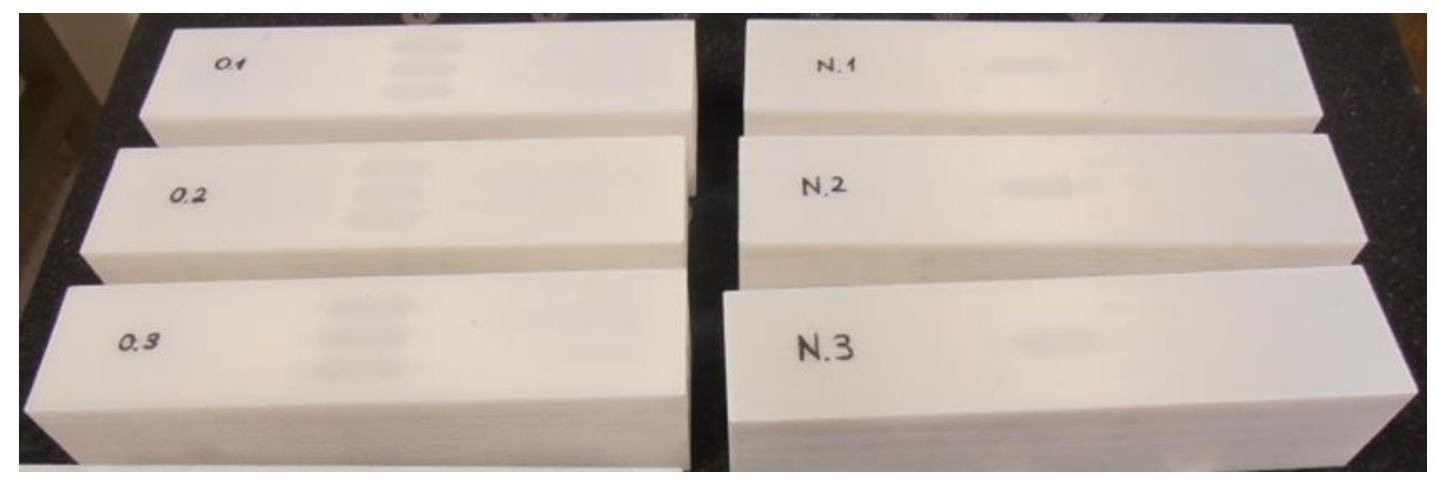

Figure 10. SLS parts manufactured.

Flexural tests were carried out according to the boundary conditions explained in section 3, with a distance between supports of $160 \mathrm{~mm}$. The load was applied with a speed of $2 \mathrm{~mm} / \mathrm{min}$ and measured with a calibrated load cell (PCE-FG1K).

Non-linear behaviour in the initial phase of the flexural test was observed. This is due to a geometry distortion that causes the positioning error as well as a non-perfect contact with the punch and the supports. However, in the final zone of the curves the behaviour was more linear. For this reason, linear regression was performed on that final zone in order to obtain the slope of the fitting line, which represents the stiffness of the part (K). Table 1 and Table 2 show the weight, stiffness and specific stiffness $\left(\mathrm{K}_{\mathrm{s}}=\mathrm{K} /\right.$ weight $)$ of each part, as well as the mean value and sample standard deviation $(\sigma)$, both for non-optimal and optimal replicas, respectively.

Table 1. Results obtained for the non-optimal replicas (SLS).

\begin{tabular}{|c|c|c|c|}
\hline Part & Weight $(\mathrm{g})$ & $\mathbf{K}(\mathbf{N} / \mathbf{m m})$ & $\mathbf{K}_{\mathbf{s}}(\mathbf{N} / \mathbf{m m} / \mathbf{g})$ \\
\hline N.1 & 134.516 & 642.77 & 4.78 \\
\hline N.2 & 137.486 & 693.18 & 5.04 \\
\hline N.3 & 136.245 & 587.10 & 4.31 \\
\hline Mean value & $\mathbf{1 3 6 . 0 8 2}$ & $\mathbf{6 4 1 . 0 2}$ & $\mathbf{4 . 7 1}$ \\
\hline Sample standard deviation & $\mathbf{1 . 4 9 2}$ & $\mathbf{5 3 . 0 6}$ & $\mathbf{0 . 3 7}$ \\
\hline
\end{tabular}


Table 2. Results obtained for the optimal replicas (SLS).

\begin{tabular}{|c|c|c|c|}
\hline Part & Weight $(\mathrm{g})$ & $\mathbf{K}(\mathbf{N} / \mathbf{m m})$ & $\mathbf{K}_{\mathbf{s}}(\mathbf{N} / \mathbf{m m} / \mathbf{g})$ \\
\hline $\mathbf{O . 1}$ & 94.954 & 808.44 & 8.51 \\
\hline $\mathbf{0 . 2}$ & 86.99 & 663.75 & 7.63 \\
\hline $\mathbf{O . 3}$ & 101.621 & 840.77 & 8.27 \\
\hline Mean value & $\mathbf{9 4 . 5 2 2}$ & $\mathbf{7 7 0 . 9 9}$ & $\mathbf{8 . 1 4}$ \\
\hline Sample standard deviation & $\mathbf{7 . 3 2 5}$ & $\mathbf{9 4 . 2 7}$ & $\mathbf{0 . 4 6}$ \\
\hline
\end{tabular}

It can be seen that the sample standard deviation of the optimal replicas is greater than that of the non-optimal replicas. Laser dispersion of the SLS machine can lead to manufacture parts not-well sintered, which means a lower density and inferior mechanical properties (Gibson and Shi 1997). This explains why the part 'O.2' has a lower mass and also a lower stiffness and specific stiffness than the other replicas ('O.1' and 'O.3').

The average stiffness of the non-optimal and optimal geometries are 641.02 and $770.99 \mathrm{~N} / \mathrm{mm}$, respectively. This means that the optimal geometry is $20.28 \%$ stiffer than the non-optimal geometry. In terms of specific stiffness, the average value of the nonoptimal geometry is $4.71 \mathrm{~N} /(\mathrm{mm} \cdot \mathrm{g})$, while the average value of the optimal geometry is $8.14 \mathrm{~N} /(\mathrm{mm} \cdot \mathrm{g}), 72.82 \%$ higher. These values do not match exactly the FEA results because there are many factors associated with the manufacturing process and the experimental test that can have an important influence on the results. However, both the experimental and FEA results show a significant improvement in the specific stiffness of the optimal geometry.

\section{Polyjet case study}

The geometry of section 3 was also lightened with an internal parameterized structure 
with 2 different materials, taking advantage of the multimaterial capability of Polyjet technology. Three replicas of the optimal geometry and three replicas of a non-optimal geometry were manufactured and tested.

\subsection{Geometry}

In this case 2 different materials (VeroBlackPlus and FullCure720) were employed in order to show the potential of multimaterial AM technologies. The flexural modulus of both materials was obtained from some flexural samples according to standard ISO 178. The mean value obtained for the VeroBlackPlus and FullCure720 was $1490.74 \mathrm{MPa}$ and 2123.92MPa respectively. These values were used for the FEA, with a Poisson's ratio of 0.3 (Colburn et al. 2001, Vesenjak et al. 2009, Gibson et al. 2010) and a density of $1.18 \mathrm{~g} / \mathrm{cm}^{3}$ and $1.19 \mathrm{~g} / \mathrm{cm}^{3}$ respectively. Since FullCure 720 is stiffer than VeroBlackPlus, FullCure720 must be located in the most stressed zones in order to do a more optimal design (Bruggi and Taliercio 2013). According to an initial FEA of the solid part, the most stressed areas are in the zone of the force application, the contact zone with the support and the lower zone of the middle cross section (Figure 11). Hence, FullCure720 must be placed in those zones, as reinforcement. 


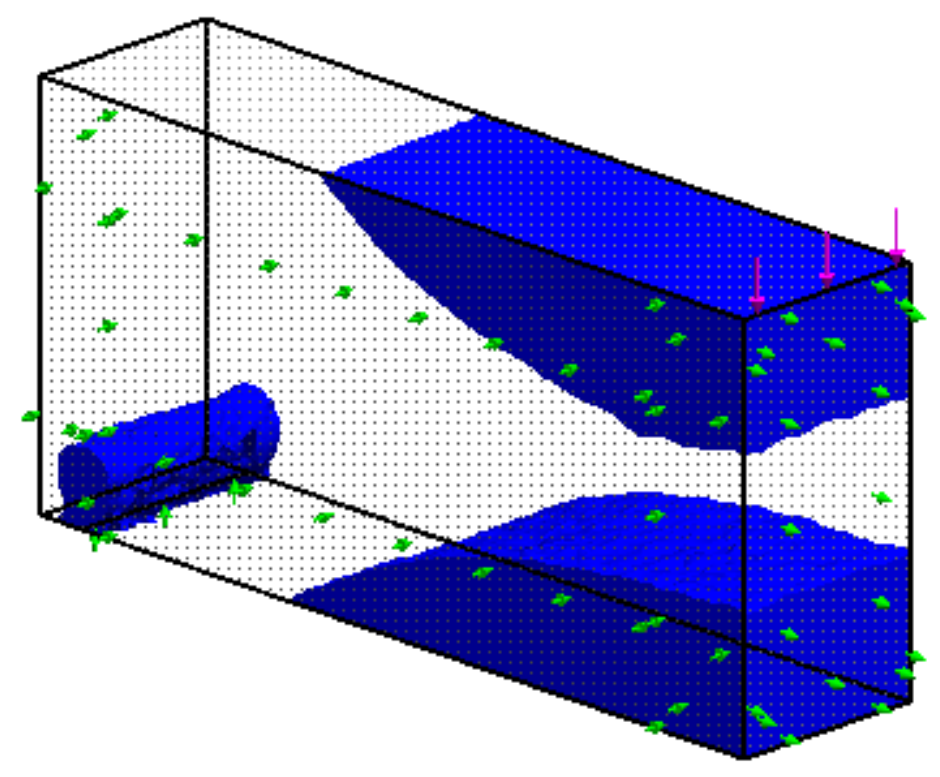

Figure 11. The most stressed areas of the geometry.

With this in mind, the design of the internal structure was carried out (Figure 12), again applying double symmetry. A total of 17 design variables were defined, associated with the length and height of the FullCure720 reinforced zones (variables from 1 to 6), thickness of the external faces (variables from 7 to 10) and the diameter of the bars in different groups (variables from 11 to 17). 


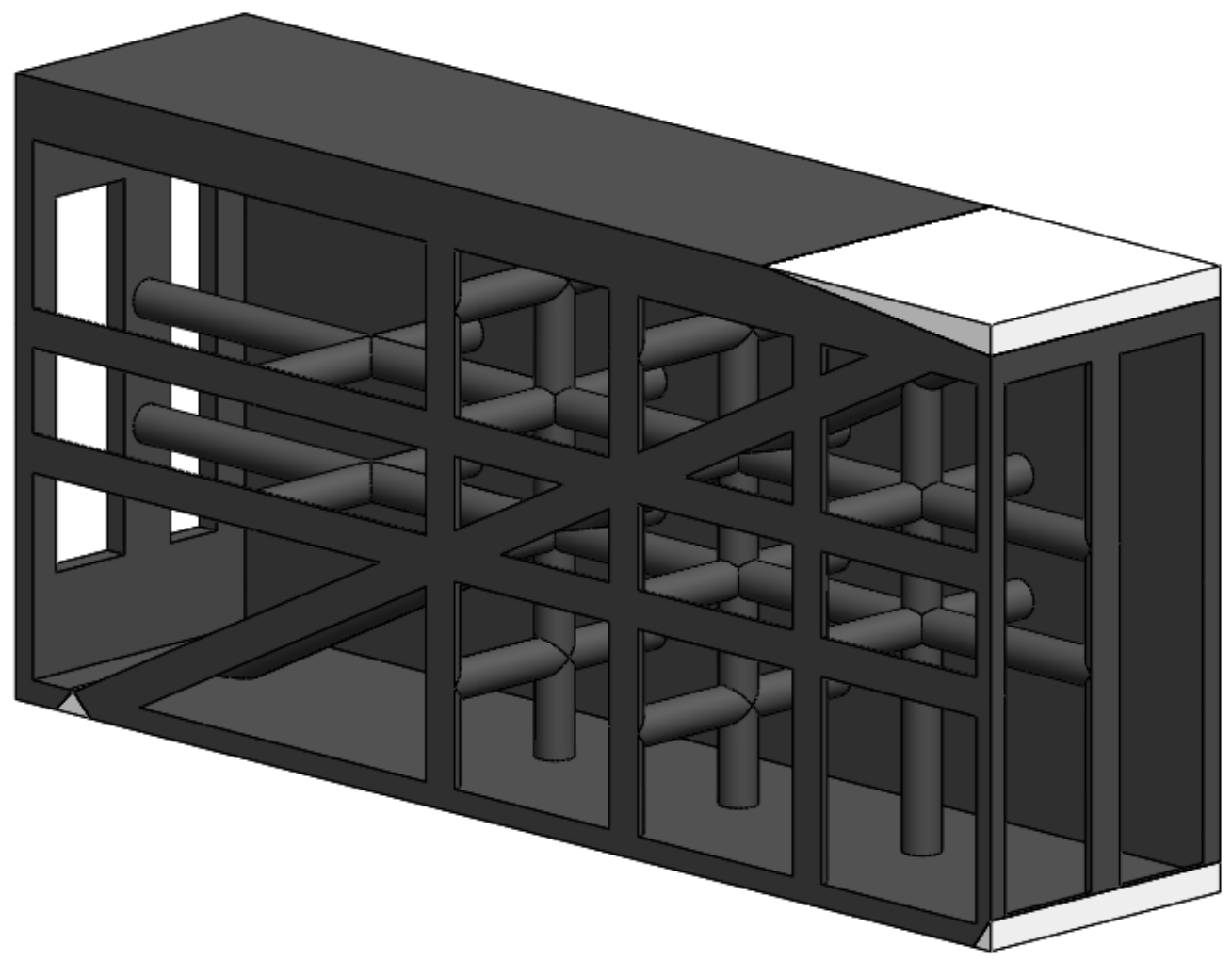

Figure 12. Polyjet case study geometry.

\subsection{Optimization}

The geometry defined in section 5.1 was optimized with 5 executions of the program described in section 2. The most representative optimum in terms of mass among the 5 optima achieved was selected to be fabricated. In this case, it was reached in execution number 2 , with a mass of $26.573 \mathrm{~g}(0.49 \mathrm{~mm}$ deflection $)$, while the average value of the 5 optima was $26.632 \mathrm{~g}$. A total of 60 designs were evaluated in this execution (the highest among the 5 executions), with a total optimization time of 68.0min (Figure 13). Figure 14 shows the variability of the design variables of the 5 optima. 


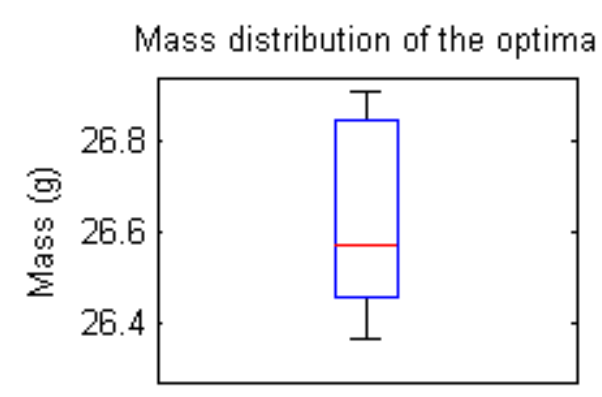

(a)

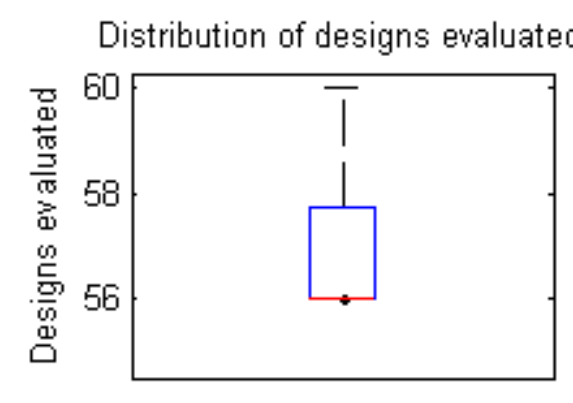

(c)

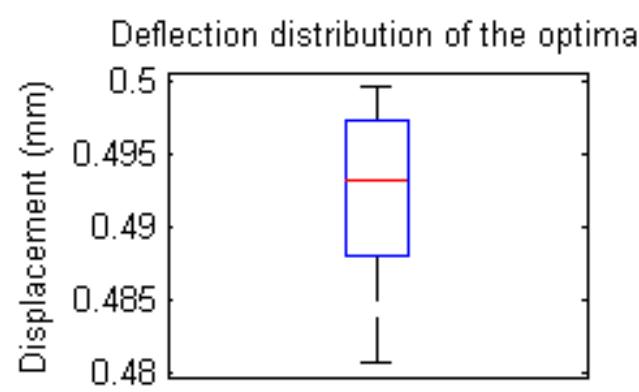

(b)

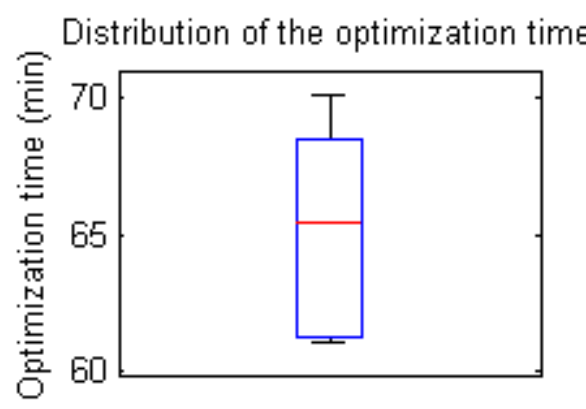

(d)

Figure 13. Distribution of mass of the optima (a), distribution of deflection of the optima (b), distribution of number of designs evaluated (c) and distribution of the optimization time (d) for the Polyjet case study. 


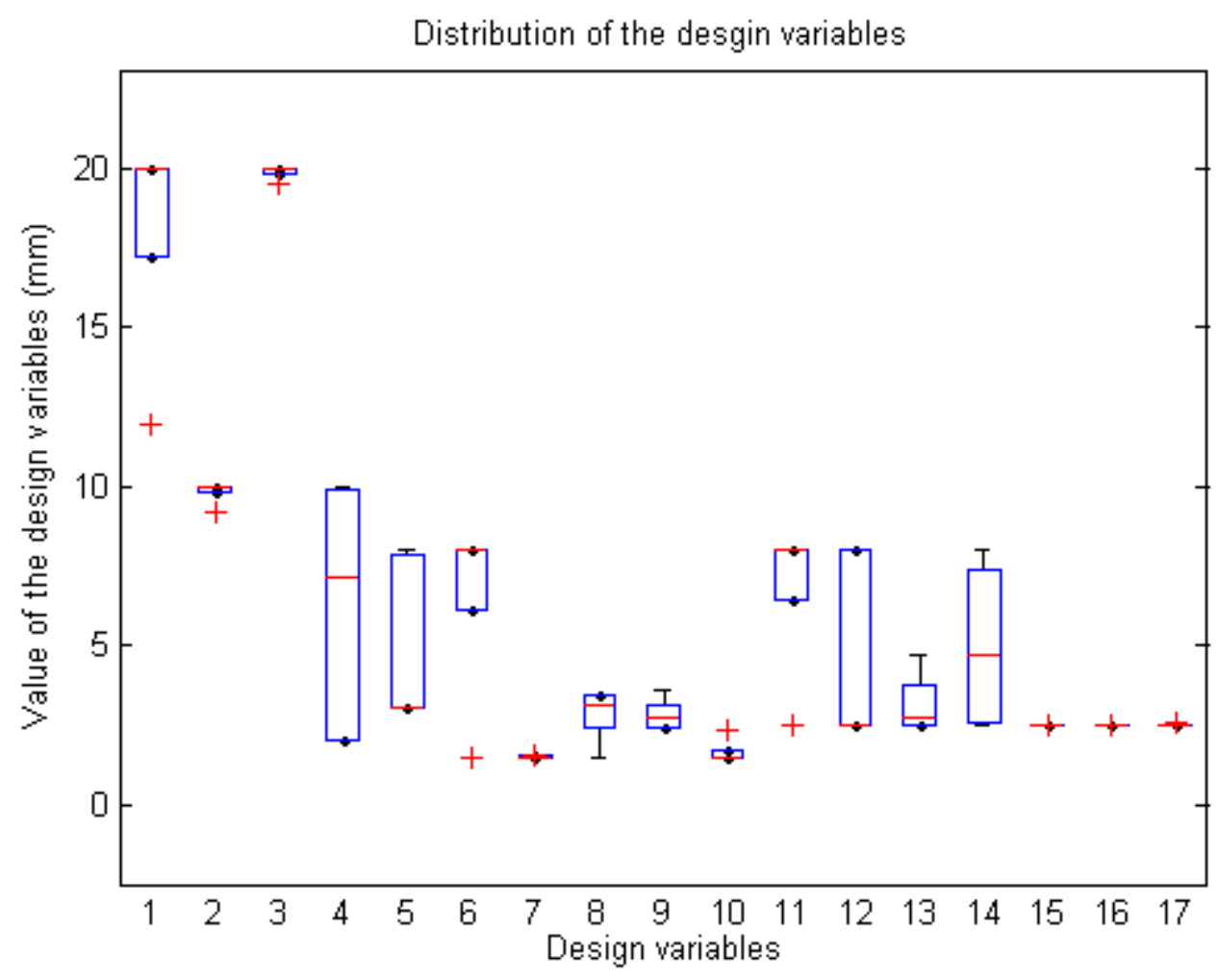

Figure 14. Distribution of the design variables of the 5 optima (Polyjet case study).

Apart from the optimum selected, a non-optimal design evaluated during execution 2 was also selected to be fabricated. The design selected was the number 9 for having the lowest specific stiffness among the designs evaluated. This design has a mass of $30.049 \mathrm{~g}$ and $0.75 \mathrm{~mm}$ of deflection.

Applying symmetry with respect to the two planes of symmetry, the design of the optimum (Figure 15) and non-optimum (Figure 16) were obtained.

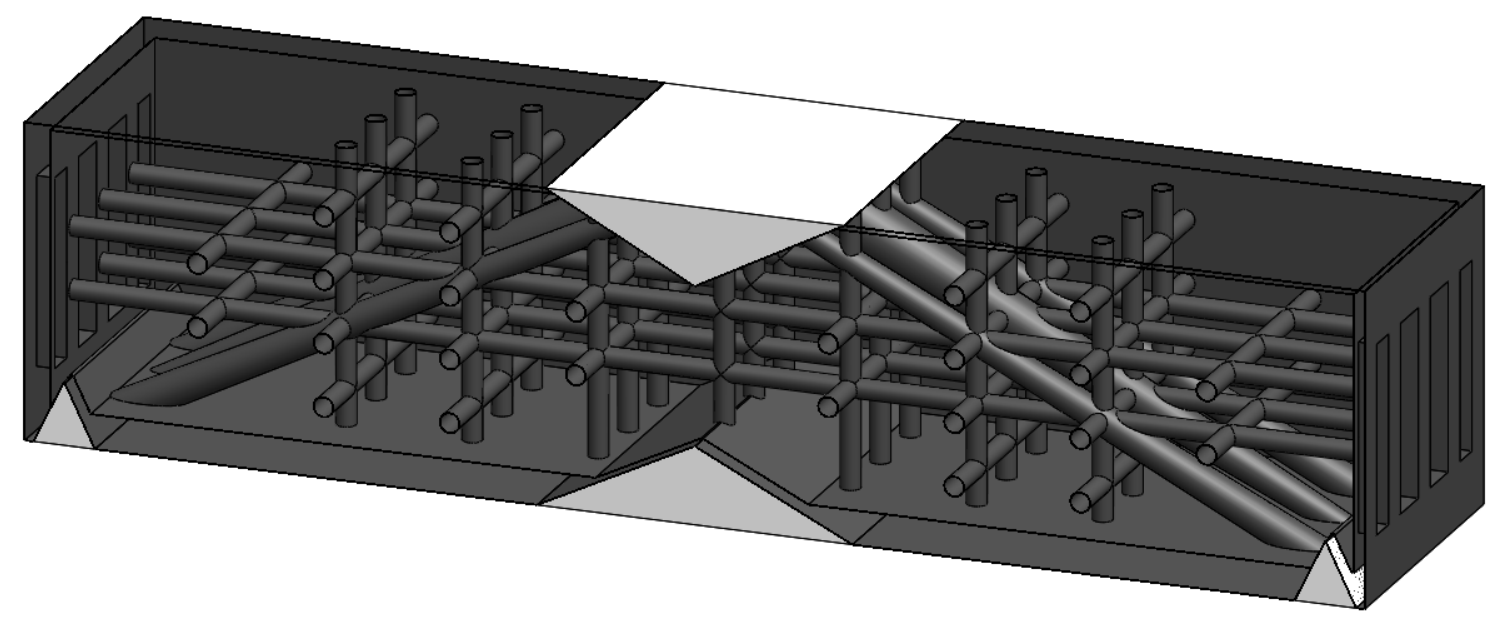


Figure 15. Optimum design selected (Polyjet case study).

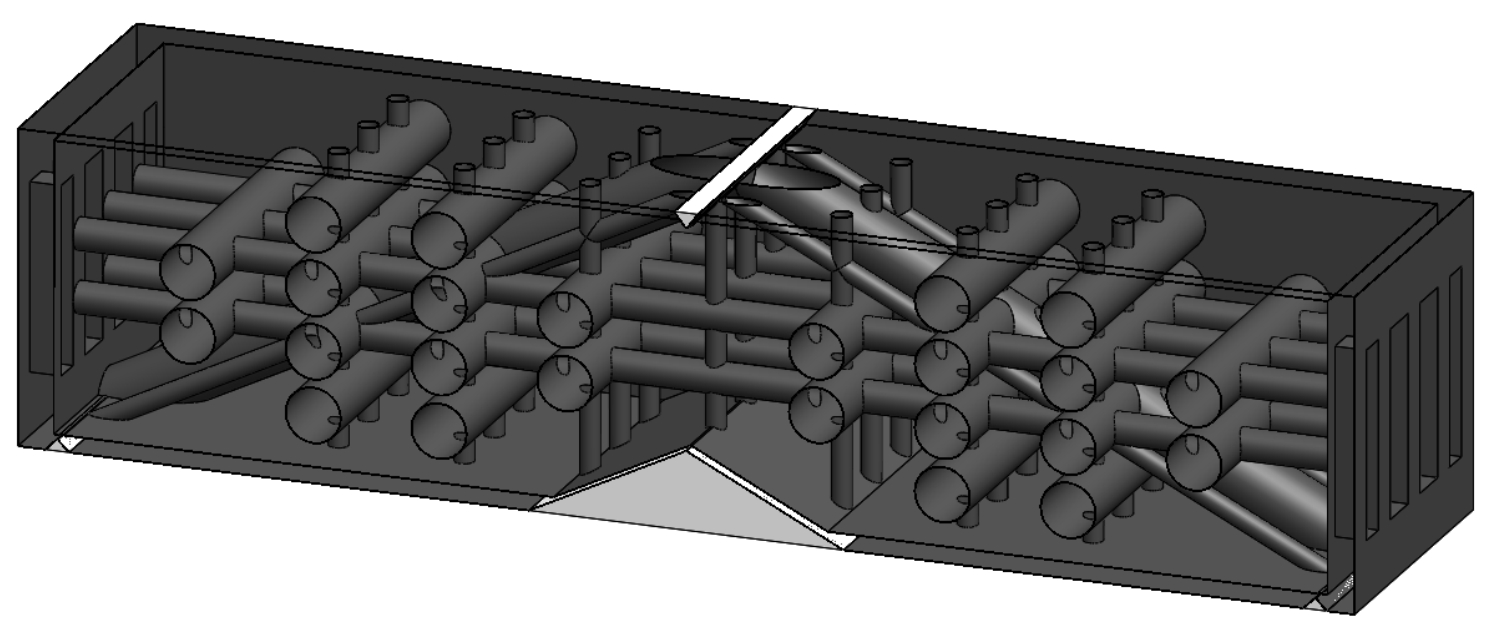

Figure 16. Non-optimum design selected (Polyjet case study).

\subsection{Parts manufacturing and flexural test}

A 3D Objet Eden 330 machine with $16 \mu \mathrm{m}$ resolution was employed to manufacture the 3 replicas of the optimum and non-optimum designs. In this case a post-processing was needed to remove the support material. This task was carried out using pressurized water and caustic 7\% $\mathrm{NaOH}$ dissolution to dissolve the support material (Cazón et al. 2014). This cleaning phase required an important effort, especially in the non-optimal parts, where the internal structure was denser and the support material extraction was more complex and laborious. This is a clear disadvantage of the Polyjet technology compared to other AM technologies where the base material serves as support material, as in SLS technology. In SLS powder that is not sintered can be easily removed from the final part. Moreover, this material is recyclable, while in the Polyjet technology is not.

Finally, the flexural tests explained in section 4.3 were applied in these parts. Table 3 and Table 4 summarize the results obtained for non-optimal and optimal parts respectively. In this case the weight deviation of both optimal and non-optimal geometries is lower than in the case of SLS, where an important deviation was observed 
specially in the optimal replicas. This same conclusion can be obtained from the flexural results. The stiffness and specific stiffness values between replicas of the same geometry are far closer than in the case of SLS.

Table 3. Results obtained for the non-optimal replicas (Polyjet).

\begin{tabular}{|c|c|c|c|}
\hline Part & Weight $(\mathbf{g})$ & K (N/mm) & $\mathbf{K}_{\mathbf{s}}(\mathbf{N} / \mathbf{m m} / \mathbf{g})$ \\
\hline N.1 & 126.026 & 297.14 & 2.36 \\
\hline N.2 & 125.68 & 288.88 & 2.30 \\
\hline N.3 & 126.051 & 286.32 & 2.27 \\
\hline Mean value & $\mathbf{1 2 5 . 9 1 9}$ & $\mathbf{2 9 0 . 7 8}$ & $\mathbf{2 . 3 1}$ \\
\hline Sample standard deviation & $\mathbf{0 . 2 0 7}$ & $\mathbf{5 . 6 5}$ & $\mathbf{0 . 0 4}$ \\
\hline
\end{tabular}

Table 4. Results obtained for the optimal replicas (Polyjet).

\begin{tabular}{|c|c|c|c|}
\hline Part & Weight $(\mathrm{g})$ & $\mathbf{K}(\mathbf{N} / \mathbf{m m})$ & $\mathbf{K}_{\mathbf{s}}(\mathbf{N} / \mathbf{m m} / \mathbf{g})$ \\
\hline $\mathbf{0 . 1}$ & 106.623 & 795.03 & 7.46 \\
\hline $\mathbf{O . 2}$ & 107.605 & 795.09 & 7.39 \\
\hline $\mathbf{0 . 3}$ & 109.834 & 756.51 & 6.89 \\
\hline Mean value & $\mathbf{1 0 8 . 0 2 1}$ & $\mathbf{7 8 2 . 2 1}$ & $\mathbf{7 . 2 4}$ \\
\hline Sample standard deviation & $\mathbf{1 . 6 4 5}$ & $\mathbf{2 2 . 2 6}$ & $\mathbf{0 . 3 1}$ \\
\hline
\end{tabular}

Moreover, experimental results were again quite different from FEA results. However, it is observed that the optimal design is stiffer and lighter than non-optimal design. The average value of stiffness of the optimal geometry $(782.21 \mathrm{~N} / \mathrm{mm})$ is 2.69 times the average value of the non-optimal $(290.78 \mathrm{~N} / \mathrm{mm})$. In terms of specific stiffness, the average value of the optimal geometry $(7.25 \mathrm{~N} / \mathrm{mm} / \mathrm{g})$ is 3.14 times the average value of the non-optimized $(2.31 \mathrm{~N} / \mathrm{mm} / \mathrm{g})$. In Figure 17 all the flexural test curves are shown 
together. It can be observed how the optimal geometries, despite being lighter, have a higher stiffness compared to non-optimal replicas.

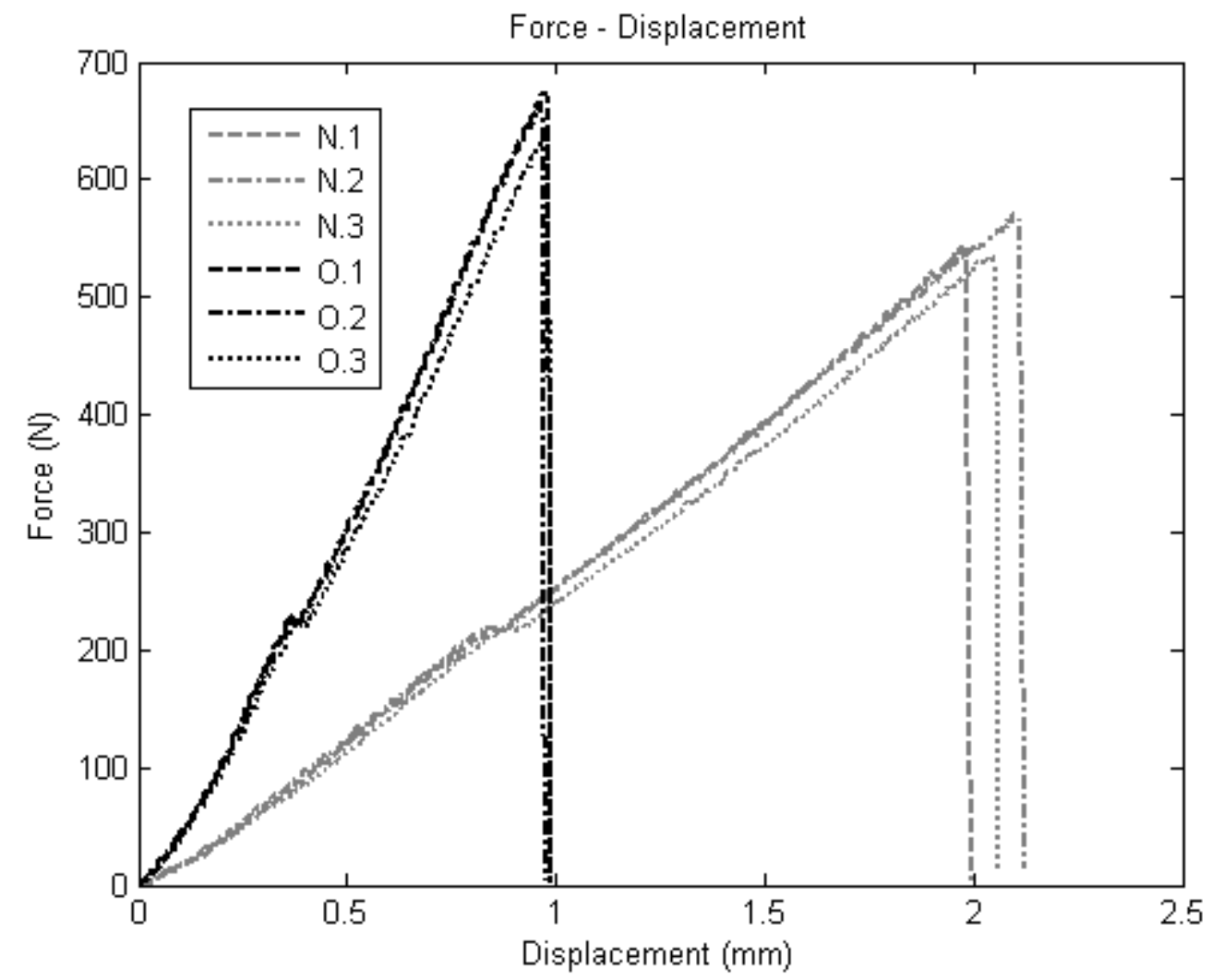

Figure 17. Force-displacements curves of the 3 replicas of non-optimal and optimal geometries (Polyjet case study).

\section{Conclusions}

A new optimization methodology based on GAs, Kriging metamodel and FEA has been proposed to lightweight optimization of AM parts. This method has been implemented in the Application Programming Interface of a commercial 3D CAD design and FEA software, and has been applied in a case study with two different internal designs adapted to SLS and multimaterial Polyjet respectively. In both cases, three replicas of the optimal and non-optimal designs were manufactured. For the Polyjet technology, the support material removal was a very laborious task, which means that this lightweight 
optimization methodology is more appropriated for AM technologies where the base material can be used as support material, or even for AM technologies where support material is not necessary.

According to the experimental results of the flexural tests, for the same design and among replicas, parts made with SLS technology present more variance than those made with Polyjet technology due to the laser dispersion in the work platform.

Comparing the results of the optimal and non-optimal geometries, both SLS and Polyjet optimal geometries have a better behaviour in terms of stiffness and specific stiffness than non-optimal parts, which means that the proposed methodology works correctly.

Although the new method proposed achieves good results, some ideas will be developed in the future work to improve the methodology. First of all, different test will be accomplished to evaluate the influence of the regression model used in the Kriging metamodel. The idea is to use the linear model when the number of data is low, and once the number of data is enough, to use the quadratic model to improve the quality of the estimations. On the other hand, this method works only with continuous variables. Therefore, the objective is to adjust the code to be able to operate with continuous and discrete variables together, allowing the parameterization of CAD features defined by discrete variables.

\section{Acknowledgements}

This work was supported by the research group of "Manufacturing Processes" and the "University Institute of Computational Engineering", both from The University of Las Palmas de Gran Canaria (ULPGC). 


\section{References}

Almeida, H.A. \& Bártolo, P.J., 2013. Topological optimisation of scaffolds for tissue engineering. Procedia Engineering, 59, 298-306 Available from: http://www.sciencedirect.com/science/article/pii/S1877705813010394

http://www.sciencedirect.com/science/article/pii/S1877705813010394\# [Accessed 2014/06/04/17:59:39].

Bruggi, M. \& Taliercio, A., 2013. Topology optimization of the fiber-reinforcement retrofitting existing structures. International Journal of Solids and Structures, 50 (1), 121-136 Available from: http://www.sciencedirect.com/science/article/pii/S0020768312003927

http://ac.els-cdn.com/S0020768312003927/1-s2.0-S0020768312003927main.pdf? tid=adfef5b8-7a1c-11e4-9de2$\underline{00000 a a c b 360 \& a c d n a t=1417522612 \_4 a b 8 c 1 a 44 d f 112 d 10 a b 2 f 610 a 1 f 4 d 714}$ [Accessed 2014/03/22/12:49:09].

Cazón, A., Morer, P. \& Matey, L., 2014. Polyjet technology for product prototyping: Tensile strength and surface roughness properties. Proceedings of the Institution of Mechanical Engineers, Part B: Journal of Engineering Manufacture, Available from: http://pib.sagepub.com/content/early/2014/04/11/0954405413518515 http://pib.sagepub.com/content/228/12/1664.full.pdf [Accessed 2014/06/03/09:40:19].

Colburn, M., Suez, I., Choi, B.J., Meissl, M., Bailey, T., Sreenivasan, S.V., Ekerdt, J.G. \& Willson, C.G., 2001. Characterization and modeling of volumetric and mechanical properties for step and flash imprint lithography photopolymers. Journal of Vacuum Science \& Technology B, 19 (6), 2685-2689 Available from: http://scitation.aip.org/content/avs/journal/jvstb/19/6/10.1116/1.1420199

http://scitation.aip.org/docserver/fulltext/avs/journal/jvstb/19/6/1.1420199.pdf?expires= $1417524000 \& \mathrm{id}=\mathrm{id} \&$ accname $=2115537 \&$ checksum $=1$ AD60F05C1820DC66D AEEB3A9972E8EE [Accessed 2014/07/26/11:02:38].

Chang, P.S. \& Rosen, D.W., 2013. The size matching and scaling method: A synthesis method for the design of mesoscale cellular structures. International Journal of Computer Integrated Manufacturing, 26 (10), 907-927 Available from: http://dx.doi.org/10.1080/0951192X.2011.650880

http://www.tandfonline.com/doi/full/10.1080/0951192X.2011.650880\#.U61X3P15PA0 http://www.tandfonline.com/doi/pdf/10.1080/0951192X.2011.650880 [Accessed 2014/06/27/11:40:51].

Chu, C., Graf, G. \& Rosen, D.W., 2008. Design for additive manufacturing of cellular structures. Computer-Aided Design and Applications, 5 (5), 686-696 Available from: http://www.tandfonline.com/doi/abs/10.3722/cadaps.2008.686-696

http://www.tandfonline.com/doi/abs/10.3722/cadaps.2008.686-696\#preview http://www.tandfonline.com/doi/pdf/10.3722/cadaps.2008.686-696 [Accessed 2014/03/22/16:23:05].

Chu, J., Engelbrecht, S., Graf, G. \& Rosen, D.W., 2010. A comparison of synthesis methods for cellular structures with application to additive manufacturing. Rapid Prototyping Journal, 16 (4), 275-283 Available from: http://www.emeraldinsight.com/journals.htm?issn=1355$2546 \&$ volume $=16 \&$ issue $=4 \&$ articleid $=1864394 \&$ show $=$ html $[$ Accessed 2014/05/28/11:00:55].

Dai, L., Gu, Y., Zhao, G. \& Guo, Y., Year. Structural shape optimization based on parametric dimension-driving and cad software integrationed.^eds., 1-8. 
Della Cioppa, A., De Stefano, C. \& Marcelli, A., 2004. On the role of population size and niche radius in fitness sharing. IEEE Transactions on Evolutionary Computation, 8 (6), 580-592 Available from: http://ieeexplore.ieee.org/xpls/abs_all.jsp?arnumber=1369248\&tag=1

http://ieeexplore.ieee.org/ielx5/4235/29964/01369248.pdf?tp=\&arnumber=1369248\&is number $=29964$.

Gibson, I., Goenka, G., Narasimhan, R. \& Bhat, N., Year. Design rules for additive manufactureed.^eds.

Gibson, I., Rosen, D.W. \& Stucker, B., 2009. Additive manufacturing technologies: Rapid prototyping to direct digital manufacturing: Springer.

Gibson, I. \& Shi, D., 1997. Material properties and fabrication parameters in selective laser sintering process. Rapid Prototyping Journal, 3 (4), 129-136 Available from: http://www.emeraldinsight.com/journals.htm?articleid $=1455147$ [Accessed 2014/08/07/08:09:52].

Hopkinson, N., Hague, R. \& Dickens, P., 2006. Rapid manufacturing: An industrial revolution for the digital age: John Wiley \& Sons.

Jin, R., Chen, W. \& Simpson, T.W., 2001. Comparative studies of metamodelling techniques under multiple modelling criteria. Structural and Multidisciplinary Optimization, 23 (1), 1-13 Available from: http://link.springer.com/article/10.1007/s00158-001-0160-4

http://download.springer.com/static/pdf/632/art\%253A10.1007\%252Fs00158-001$0160-$

4.pdf?auth66=1417522596_06b5b4c7d403a323c83e96b80a78638a\&ext=.pdf [Accessed 2014/08/09/21:01:03].

Kruth, J.P., Leu, M.C. \& Nakagawa, T., 1998. Progress in additive manufacturing and rapid prototyping. CIRP Annals - Manufacturing Technology, 47 (2), 525-540 Available from:

http://www.sciencedirect.com/science/article/pii/S0007850607632405 [Accessed 2014/08/15/11:53:08].

Lee, J.-H., Hwang, S.-C., Park, J.H. \& Lee, K.-H., Year. Structural design examples using metamodel-based approximation modeled.^eds.World Scientific and Engineering Academy and Society (WSEAS), 153-156.

Lophaven, S.N., Nielsen, H.B. \& Søndergaard, J., 2002. A matlab kriging toolbox. Technical University of Denmark, Kongens Lyngby, Technical Report No. IMMTR-2002-12, Available from: http://www.imm.dtu.dk/ hbn/dace/dace.pdf [Accessed 2014/07/18/07:55:22].

Marjanovic, N., Isailovic, B. \& Blagojevic, M., 2009. Structural optimization in cad software. Optimization, 10 (1), 27-32 Available from: http://www.mdesign.ftn.uns.ac.rs/pdf/2009/027-032_for_web.pdf [Accessed 2014/03/21/18:25:02].

Muraru, L., Pallari, J., Creylman, V., Vander Sloten, J. \& Peeraer, L., Year. Sls nylon 12 characterization through tensile testing and digital image correlation for finite element modelling of foot and ankle-foot orthosesed.^eds.

Roman Gatzi, M.U., 2000. Structural optimization tool using genetic algorithms and ansys. Available from:

http://www.researchgate.net/publication/255633327_Structural_Optimization_T ool_using_Genetic_Algorithms and Ansys.

Rosen, D.W., 2007. Computer-aided design for additive manufacturing of cellular structures. Computer-Aided Design and Applications, 4 (5), 585-594 Available from: http://www.tandfonline.com/doi/abs/10.1080/16864360.2007.10738493 
http://www.tandfonline.com/action/cookieAbsent [Accessed 2014/07/15/11:13:45].

Rubén, P., Mario, M., Gabriel, W., Fernando, O. \& Begoña, G., Year. Design optimization with gas and surrogate models for lightening parts made by additive manufacturinged.^eds. The Tenth International Conference on Evolutionary and Deterministic Methods for Design, Optimization and Control with Applications to Industrial and Societal Problems, 179-182.

S N Lophaven, H.B.N., 2002. Aspects of the matlab toolbox dace. Available from: http://www.researchgate.net/publication/235709885_Aspects_of_the_Matlab_T oolbox_DACE.

Sachlos, E. \& Czernuszka, J.T., 2003. Making tissue engineering scaffolds work. Review: The application of solid freeform fabrication technology to the production of tissue engineering scaffolds. Eur Cell Mater, 5 (29), 39-40 Available from: http://www.ecmjournal.org/journal/papers/vol005/pdf/v005a03.pdf?referer=ww w.clickfind.com.au [Accessed 2014/08/08/18:18:20].

Vesenjak, M., Öchsner, A. \& Ren, Z., 2009. Computational modelling of closed- and open-cell cellular structures with fillers. In Zhao, H. \& Fleck, D.N.A. eds. Iutam symposium on mechanical properties of cellular materials. Springer Netherlands, 197-206.

Wang, H., Chen, Y. \& Rosen, D.W., 2005. A hybrid geometric modeling method for large scale conformal cellular structures. 421-427 Available from: http://dx.doi.org/10.1115/DETC2005-85366

http://proceedings.asmedigitalcollection.asme.org/proceeding. aspx ?articleid=1588169 [Accessed 2014/03/22/19:32:30].

Wang, H.V. \& Rosen, D.W., 2001. Computer-aided design methods for the additive fabrication of truss structure. School of Mechanical Engineering, Georgia Institute of Technology.

Wong, K.V. \& Hernandez, A., 2012. A review of additive manufacturing. ISRN Mechanical Engineering, 2012 Available from: http://www.hindawi.com/journals/isrn.mechanical.engineering/2012/208760/abs I

http://downloads.hindawi.com/journals/isrn/2012/208760.pdf [Accessed 2014/08/08/10:54:21].

Yang, S., Leong, K.-F., Du, Z. \& Chua, C.-K., 2001. The design of scaffolds for use in tissue engineering. Part i. Traditional factors. Tissue Engineering, 7 (6), 679-689 Available from: http://online.liebertpub.com/doi/abs/10.1089/107632701753337645 [Accessed 2014/08/08/19:06:11].

Yeong, W.-Y., Chua, C.-K., Leong, K.-F. \& Chandrasekaran, M., 2004. Rapid prototyping in tissue engineering: Challenges and potential. Trends in Biotechnology, 22 (12), 643-652 Available from: http://www.sciencedirect.com/science/article/pii/S0167779904002926

http://ac.els-cdn.com/S0167779904002926/1-s2.0-S0167779904002926main.pdf? tid=fbcdacca-7a1d-11e4-b47600000aacb35d\&acdnat $=1417523172 \_03 f 8 f 88 b e 16 c 320647 \mathrm{e} 94 \mathrm{dc} 338 \mathrm{~b} 75 \mathrm{c} 37$ [Accessed 2014/08/08/19:06:19].

Yoo, D.-J., 2011. Computer-aided porous scaffold design for tissue engineering using triply periodic minimal surfaces. International Journal of Precision Engineering and Manufacturing, 12 (1), 61-71 Available from: http://link.springer.com/article/10.1007/s12541-011-0008-9 
http://link.springer.com/article/10.1007\%2Fs12541-011-0008-9\#page-1

http://download.springer.com/static/pdf/452/art\%253A10.1007\%252Fs12541-011$\underline{0008-}$

9.pdf?auth66=1417522471_d08f772a1aa671f693fa4a757284846d\&ext=.pdf [Accessed 2014/03/22/18:29:08].

Zhu, P., Zhang, Y. \& Chen, G.L., 2009. Metamodel-based lightweight design of an automotive front-body structure using robust optimization. Proceedings of the Institution of Mechanical Engineers, Part D: Journal of Automobile Engineering, 223 (9), 1133-1147 Available from: http://pid.sagepub.com/content/223/9/1133

http://pid.sagepub.com/content/223/9/1133.full.pdf [Accessed 2014/08/05/18:57:54]. 